DOI: 10.17516/1997-1370-0711

УДК 796.062

\title{
Project Approach for Improving the Efficiency of Sports Facilities
}

\author{
Aleksandr L. Voinich, Aleksandr I. Chikurov, \\ Aleksandra S. Il'ina and Mariila A. Sennikova* \\ Siberian Federal University \\ Krasnoyarsk, Russian Federation
}

Received 31.10.2020, received in revised form 24.12.2020, accepted 26.01.2021

\begin{abstract}
This article considers the place of the project approach in the system of management sciences. It also provides a brief description of the processes of its formation and development. The content analysis of 40 web resources has revealed an extremely low involvement of sports facilities in the project activities in the Krasnoyarsk Krai. Thus, only $45 \%$ of sports facilities have signs of project activities. At the same time, only $10 \%$ of sports facilities implement their own projects. By means of correlation and graphical analysis it is established that in the Krasnoyarsk Krai the involvement of sports facilities in project activities is not a decisive factor in their effectiveness (the correlation coefficient is not more than $2 \%$ ). At the same time, economic modeling based on the "Horseback riding in 'Gremyachaya griva' eco-park" project shows the unrealized potential of the project approach as a significant factor in the effectiveness of sports facilities.
\end{abstract}

Keywords: project method, project approach, project management, sports facility management, efficiency of sports facilities.

Research area: physical education, sports training, health-improving and adaptive physical culture: management in the physical culture system.

Citation: Voinich, A.L., Chikurov, A.I., Il'ina, A.S., Sennikova, M.A. (2021). Project approach for improving the efficiency of sports facilities. J. Sib. Fed. Univ. Humanit. Soc. Sci., 14(2), 193-205. DOI: $10.17516 / 1997-1370-0711$.

(C) Siberian Federal University. All rights reserved

* Corresponding author E-mail address: Aleksandr.Voynich@mail.ru, Chikurov71@mail.ru, alexilina1996@mail.ru, kikoro@ mail.ru

ORCID: 0000-0003-0172-4898 (Voinich) 


\title{
Проектный подход как фактор повышения
} эффективности спортивных сооружений

\author{
А.Л. Войнич, А.И. Чикуров, \\ А.С. Ильина, М.А. Сенникова \\ Сибирский федеральный университет \\ Российская Федерачия, Красноярск
}

\begin{abstract}
Аннотация. Рассмотрено место проектного подхода в системе наук об управлении, а также приведено краткое описание процессов его становления и развития. Дополнительно представлены особенности проектной деятельности в сфере управления спортивными сооружениями. Посредством проведенного контент-анализа 40 веб-ресурсов установлена крайне низкая вовлеченность в проектную деятельность спортсооружений Красноярского края. Так, только 45 \% из них имеют признаки осуществления проектной деятельности. При этом лишь $10 \%$ спортсооружений реализуют собственные проекты. Посредством корреляционного и графического анализа установлено то, что вовлеченность спортивных сооружений Красноярского края в проектную деятельность не является значимым фактором их эффективности (коэффициент корреляции не более 2 \%). В то же время проведенное экономическое моделирование на примере проекта «Конные прогулки в эко-парке «Гремячая грива» показывает нереализованные возможности проектного подхода как значимого фактора эффективности спортивных сооружений.
\end{abstract}

Ключевые слова: проектный метод, проектный подход, проектное управление, управление спортивными сооружениями, эффективность спортивных сооружений.

Научная специальность: 13.00.04 - теория и методика физического воспитания, спортивной тренировки, оздоровительной и адаптивной физической культуры: управление в системе физической культуры.

\section{Введение}

В настоящее время в сфере физической культуры и спорта (ФКиС) и физкультурнооздоровительных услуг в качестве инструмента стратегического планирования используется программно-целевой подход. Его применение дает возможность сконцентрировать ресурсы для достижения масштабной цели, исключив их распыление. Однако использование программно-целевого подхода не исключает сбои в управлении, которые порождаются отсутствием в ходе его применения должного уровня межведомственной координации, элемента творчества, гибкости, четкого плана действий и персонификации ответственности (Skopin, 2012; Kozhevnikov, 2016). На более низком уровне управления (уровне деятельности конкретных учрежде- ний отрасли ФКиС) доминирует функциональный подход. Данный подход также имеет недостатки, которые проявляются в том, что при его использовании учреждения становятся неповоротливыми, бюрократичными и даже архаичными (Kozhevnikov, 2016; Stadnichenko, 2017).

Важная особенность проектного подхода (ПП) в управлении - четкая ориентация на цель, рациональное планирование ресурсов и этапов достижения цели. Кожевников отмечает, что использование ПП позволяет экономить 20-30 \% времени и 15-20 \% затрачиваемых на достижение цели средств (Kozhevnikov, 2016). В некоторых развитых странах, например Австралии, необходимость использования ПП в деятельности государственных учреждений установлена 
на системном уровне (Biiak, Nenuzhenko, 2017). Однако в сфере государственного управления РФ и, в частности, в отрасли ФКиС ПП только начинает находить свое применение и пока является малозначимым фактором (Olkhovskii et al., 2018). Таким образом, имеет место сложившееся в системе государственного и муниципального управления РФ и отрасли ФКиС противоречие, которое заключается в том, что ПП применим еще ограниченно, однако потенциал его эффективности весьма значителен. В этой связи оценка текущего статуса и потенциала ПП в разрезе повышения эффективности управления физкультурно-спортивных сооружений Красноярского края (ФСС КК) признана актуальной задачей, что и определило направление исследований. Цель исследования состояла в выявлении значения и возможностей проектного подхода как фактора эффективности ФСС КК.

\section{Концептологические}

основания исследования

Место проектного подхода

в системе наук об управлении

Развитие науки об управлении в XX веке породило большое количество стержневых и смежных научных дисциплин: теорию управления, методологию управления, менеджмент, общую теорию систем, системный подход и системный анализ, кибернетику, теорию игр, теорию графов, исследование операций и т. д. (Novikov, 2011; Bertalanffy, 1960; Wiener, 1948; Venttsel'; 1972; Gubko, Novikov, 2005; Degtiarev, 1996; Burkov, 2011). Однако лавинообразный рост количества дисциплин в науке об управлении привел к некоторому отчуждению менеджмента от математических, или «количественных», дисциплин (Novikov, 2011). Так, менеджеры-практики не всегда могут грамотно использовать математические инструменты для проведения анализа ситуации. Напротив, математики, специализирующиеся в области управления, узконаправленно концентрируются на «технических» аспектах управления. Кроме того, следует отметить, что большинство дисциплин науки об управлении оторваны от социологии. Это обстоятельство ведет к тому, что управленцами не учитываются глобальные социальные факторы и процессы, которые могут влиять на управляемую ими систему. В этой связи актуальным может быть подход, используемый в достаточно общей теории управления, при котором управление рассматривается через призму социальной структуры общества и полной функции управления (DOTU, 2011) (рис. 1). Так, управление по полной функции включает несколько этапов (DOTU, 2011):

1) опознавание фактора среды, который вызывает потребность в управлении;

2) формирование стереотипа распознавания данного фактора (на будущее);

3) формирование вектора цели управления в отношении фактора;

4) формирование концепции управления для достижения цели;

5) организацию и реорганизацию управляющей структуры;

6) контроль за деятельностью структуры;

7) ликвидацию/реорганизацию структуры в случае необходимости.

Последние три пункта (5-7) полной функции управления можно отнести к классическому менеджменту (управлению организацией) (рис. 1). При этом ПП или проектное управление (ПУ) являются составной частью менеджмента как практикоориентированной научной дисциплины (см. правую нижнюю часть рис. 1). Остальные практико-ориентированные дисциплины в области управления, как и ПП, могут давать инструментарий для разработки того или иного практического решения в рамках целостного управления по полной функции. При этом методология управления (правая верхняя часть рис. 1) позволяет концептуально направить процесс поиска управленческих решений. Такой взгляд на управление и ПП представляется авторам более целостным, нежели тот, что представлен в классической литературе по управлению.

\section{Становление и развитие проектного управления}

Становление ПУ в ХХ столетии обозначило переход от функционального и про- 


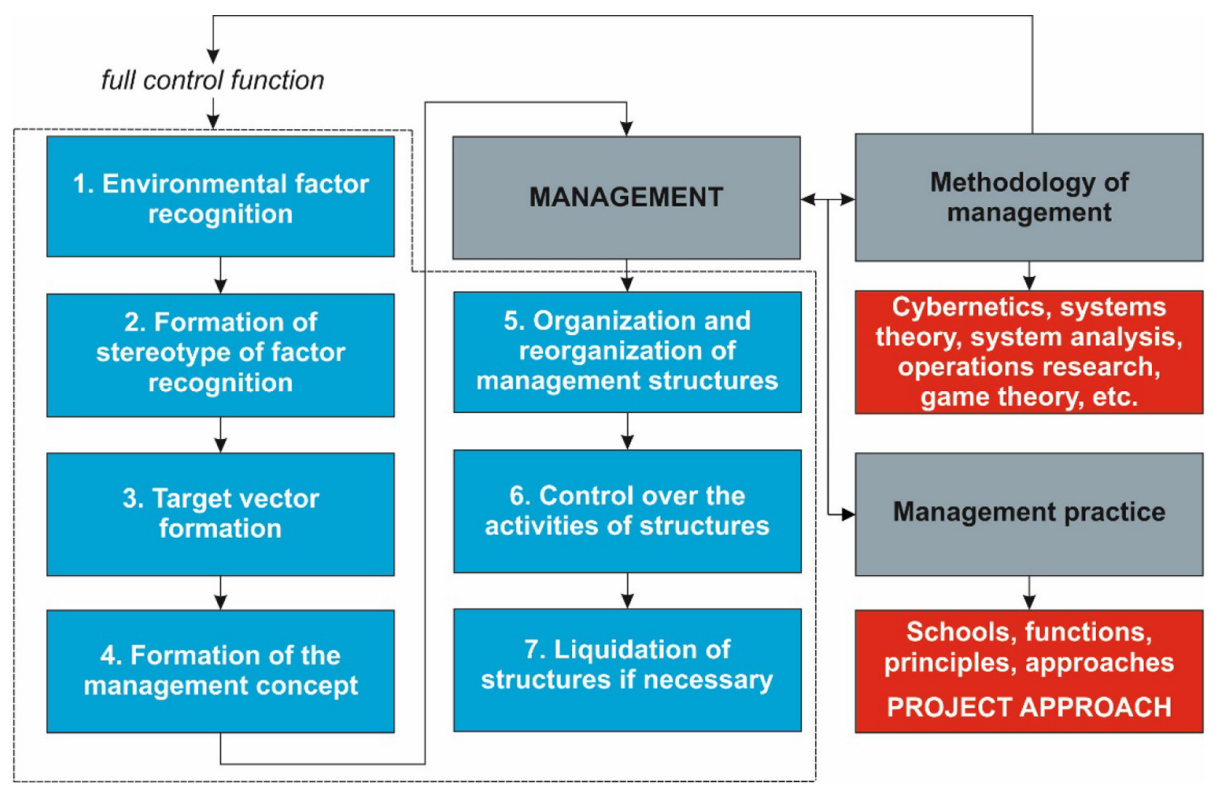

Рис. 1. Взаимосвязь полной функции управления, менеджмента, теории и практики управления, проектного подхода

Fig. 1. Relationship of full control function, management, methodology of management, management practice, project approach

цессного подходов в управлении к более динамичной модели управления. Как отмечает Трофимов, движущим фактором, определившим возникновение ПУ, стало ускорение научно-технического прогресса, выраженного в уменьшении периода времени, прошедшего с момента появления идеи до ее реализации. Также возникновение ПУ обусловлено потребностью в точном планировании работ с целью минимизации затрат (Trofimov, 2019).

Появление ПУ обычно связывают с именем Генри Гантта, который в 1917 году опубликовал свои первые работы в этой области (Zarenkov, 2006). В настоящее время диаграмма Г. Гантта, названная в его честь, является неотъемлемым атрибутом ПУ. Дальнейшее развитие ПУ связано с разработкой в 1937 году американским ученым Лютером Гуликом матричной организационной схемы управления (Zarenkov, 2006), которая объединила преимущества функциональной и проектной схем организации работ. В 1940-50-х годах внедрение ПУ в обороннопроизводственной сфере США позволило реализовать такие технически сложные проекты как разработка бомбардировщика «Б-52» и подводной лодки «Солярис». К концу 1950-х годов эффективность ПУ была признана НАСА. С 1960-70-х годов произошел процесс перехода ПУ из оборонной сферы в гражданскую. В 1969 году в США был основан Институт Управления Проектами (Project Management Institute, PMI). А в 80-90-е годы прошлого века необходимость в использовании ПУ была признана практически повсеместно (Trofimov, 2019; Zarenkov, 2006; Mironenko, Leonova, 2017).

В настоящее время в мире существует развитая сеть учреждений, занимающихся обучением и сертификацией в области ПУ: PMI (США), IPMA (Швейцария) - Международная Ассоциация Управления Проектами и другие организации. В 1990 году в России была основана Российская Ассоциация Управления Проектами («СОВНЕТ»), также занимающаяся обучением и сертификацией в области ПУ и являющаяся корпоративным членом IPMA.

На текущий момент времени ПП и ПУ внедряются в систему управления государств 
во многих странах мира. Так, например, в Великобритании в 2011 году создан Департамент Приоритетных Проектов (Major Projects Authority) в виде проектного офиса. В его задачи входит экспертная поддержка реализации государственных проектов. Подобные проектные офисы существуют в Австралии, Сингапуре и Канаде (Biiak, Nenuzhenko, 2017).

В последнее время в РФ ПУ также внедряется в систему государственного планирования и управления. Прежде всего, данный процесс реализуется на федеральном уровне. В 2016 году в аппарате Правительства РФ был создан Департамент Проектной Деятельности, курирующий реализацию национальных проектов (Biiak, Nenuzhenko, 2017). Также в 2016 году создан Совет при Президенте РФ по стратегическому развитию и приоритетным проектам. Эта структура по своим функциям тоже представляет собой проектный офис. В настоящее время в нашей стране развернута реализация 13 национальных проектов. Внедрение ПУ проходит и на региональном уровне. Так, например, Кожевников отмечает положительный опыт внедрения ПУ в Белгородской области, которое началось еще в 2010 году. В Красноярском крае в соответствии с федеральной повесткой и поручениями Президента, а также Председателя Правительства РФ в декабре 2016 года в структуре аппарата Правительства края создано Управление проектной деятельности.

Тем не менее анализ работ (Skopin, 2012; Kozhevnikov, 2016; Biiak, Nenuzhenko, 2017; Savchenko, Mikhailova, 2017) и наблюдения показывают, что до полноценного внедрения ПП в систему государственного управления еще очень далеко. Что касается сферы физкультурно-спортивных услуг, то Скопин отмечает то, что, несмотря на значительное количество мероприятий в данной сфере, ПП в ней научно обоснованного применения не находит (Skopin, 2012).

\section{Проектный подход в управлении спортсооружсениями}

Для классификации процессов ПУ в управлении физкультурно-спортивными сооружениями (ФСС) использованы, прежде всего, информационные ресурсы в области системы стратегического планирования РФ. Авторами проведен анализ профильной литературы по управлению ФСС (Sawyer et al., 2015; Fried, 2015; Dugalić, Krsteska, 2013) с позиции системного анализа процессов в среде ФСС и вычленения из них процессов, имеющих признаки проектной деятельности. В результате такой аналитической работы была составлена схема, отраженная на рис. 2.

Согласно предложенной схеме, все процессы ФСС, имеющие признаки проектной деятельности, можно классифицировать на внешние, исходящие из надсистемы (например, отраслевые проекты - Универсиады, проекты «ВФСК ГТО», «Спорт - норма жизни» и др.), и внутренние, реализуемые в границах системы (ФСС) как самостоятельные проекты. При этом два процесса (строительство и демонтаж ФСС) протекают до появления ФСС и в конце его жизненного цикла. Таким образом, в рамках текущей работы ФСС проектная деятельность может реализовываться только в виде мероприятий, локальных проектов, нацеленных на получение уникальных продуктов, текущего и локального ремонтов. По нашему мнению, такая композиционная схема дает управленцу ФСС системный взгляд на то, в каких процессах и на каких этапах жизненного цикла ФСС возможно использовать инструментарий ПУ.

Как отмечает Обожина, одним из главных требований к руководителям спортивных учреждений являются профессиональные компетенции в области управления (Obozhina, 2017). В этой связи представляется справедливым отнести к таковым и умение грамотно использовать ПУ в тех или иных процессах и ситуациях в пространстве ФСС.

\section{Методы исследования}

В ходе проведенного в 2019 году исследования авторами были применены следующие научные методы: ретроспективный анализ, системный анализ, контент-анализ, анализ экономической эффективности использования ФСС, корреляционный и графический анализ, анкетирование и моделирование.

Ретроспективный анализ был использован для обработки литературных источников 


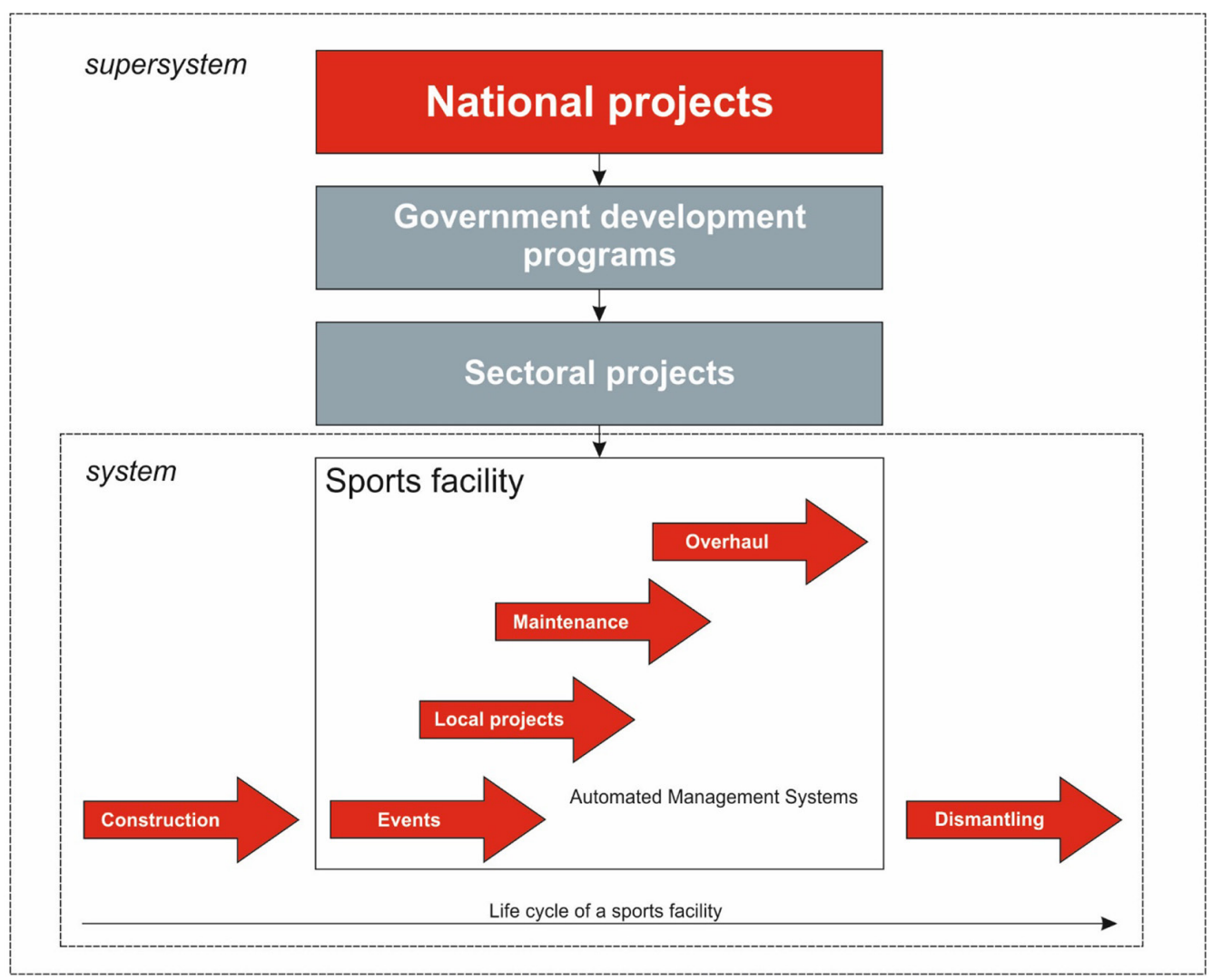

Рис. 2. Проектная деятельность в разрезе жизненного цикла ФСС

Fig. 2. Project activities in relation to the life cycle of sports facilities

и проводился по следующему алгоритму: 1. Выделение ключевых запросов для проведения литературного поиска. 2. Формирование поисковой матрицы, включающей ключевые запросы и информационные базы данных. 3. Поиск и библиографическая систематизация литературных источников. 4. Скрининг и критический анализ содержания литературных источников. 5. Отбор наиболее релевантных литературных источников. 6. Выделение ключевых информационных элементов. 7. Выстраивание логического ряда из ключевых информационных элементов в ретроспективном ключе. Для проведения ретроспективного литературного анализа использованы следующие информационные источники: поисковая система «Яндекс», поисковая система «Google», поисковая система «Google.Академия», электронные ресурсы Российской государственной би- блиотеки, научная электронная библиотека «Cyberleninka», научно-поисковый сервис «ResearchGate.net», peсурсы Библиотечноиздательского комплекса Сибирского федерального университета. Глубина поиска лимитировалась 100 источниками на каждый ключевой запрос. Для ключевых запросов применены слова и словосочетания «проект», «проектный метод», «проектный подход», «проектное управление», «управление спортивными сооружениями», «эффективность спортивных сооружений».

Системный анализ использовался с позиции рассмотрения структуры операционной деятельности ФСС (Degtiarev, 1996). Для того чтобы выделить процессы с помощью ПП в ФСС КК, осуществлялся анализ текущей деятельности ФСС как по литературным источникам (Sawyer et al., 2015, Fried, 2015; Dugalić, Krsteska, 2013; Obozhina, 2017; Pereverzin, 
2006; Pochinkin, 2010), так и в аспекте практической деятельности ФСС КК. При этом анализ проводили в разрезе жизненного цикла ФСС. Такой подход позволил дать системный взгляд на статус и значение ПП в деятельности и жизненном цикле ФСС.

Контент-анализ был необходим для рассмотрения уровня вовлеченности ФСС КК в проектную деятельность. Разработка и адаптация методики контент-анализа проводилась на основе основных принципов методологии контент-анализа (Tarshis, 2013) и ее прикладных интерпретаций (Vershlovskii, 2006). Полученная таким образом методика контент-анализа включала следующие этапы: 1) выделение совокупности анализируемых текстов - в качестве таковых брали совокупность текстовых материалов на веб-ресурсах учреждений (наполнение сайтов), представляющих то или иное ФСС; 2) формирование смысловых единиц (юнитизация) анализа, в качестве которых были использованы следующие слова и словосочетания: а) «проект»; б) «проект + имя»; в) «проект + имя + цель + сроки». В случае нахождения в тексте варианта «а» учреждению присваивался 1 балл, варианта «б» - 2 балла, варианта «в»-3 балла. Каждая оценка (балл) давалась за строго определенный отдельный контекст и не дублировалась. Это означает, например, что при двукратном использовании слова «проект» в одном контексте (смысловом блоке) давался только 1 балл. Если контекст менялся, то при нахождении в новом контексте слова «проект» давался дополнительный 1 балл и т. д. Также дополнительные баллы (4 балла) присваивались учреждениям за наличие или трансляцию проектной деятельности, которая носила отраслевой характер (федеральный масштаб). То есть при нахождении на вебресурсах учреждений информации, рекламы, баннеров, на которых транслировалась информация по таким, например, федеральным проектам, как ВФСК «ГТО», «Спорт - норма жизни» и т. д., добавляли дополнительные 4 балла. На 3-м этапе проводилось изучение содержания веб-ресурсов на предмет наличия смысловых единиц текста. На 4-м этапе производилось заполнение специально подготовленной таблицы и подсчет суммы баллов. Полагалось, что чем больше была заработанная учреждением сумма баллов, тем больший уровень вовлеченности в проектную деятельность имело учреждение (ФСС). Всего контент-анализу были подвергнуты 40 веб-ресурсов ФСС КК, имеющих различную географию (Красноярск, Железногорск, Канск, Лесосибирск, Бородино, Норильск и др.) и широкий диапазон организационноправовых форм.

Анализ экономической эффективности ФСС проводили с использованием элементов методики Москомспорта (Zubarev et al., 2008). В рамках анализа экономической эффективности ФСС осуществляли расчет одного показателя - доходности ФСС. Для проведения расчетов использовали данные по выручке и общей сумме расходов ФСС. В качестве показателя экономической эффективности был выбран показатель доходности ФСС, определяемый по соответствующей формуле (1):

Доходность $=\frac{\text { Выручка от оказанных платных услуг }}{\text { Общая сумма расходов }} \times 100 \% .(1)$

Исходные данные для анализа заимствовали на веб-ресурce bus.gov.ru. Такой подход позволял получить надежные данные по экономической эффективности при простоте процедуры анализа.

Корреляционный анализ применяли для оценки зависимости экономической эффективности от вовлеченности ФСС КК в проектную деятельность и проводили в соответствии с общепринятыми подходами в области математической статистики (Puchkov, 2013). Для наглядности отображения полученной корреляции использован метод графического представления информации и анализ облака точек.

В финальной части исследовательской работы были использованы методы экономического моделирования и анкетирования. Процедура моделирования представляла собой построение модели экономической эффективности проекта «Конные прогулки в эко-парке «Гремячая грива». Для расчета экономической эффективности проводили опрос потенциальных клиентов эко-парка «Гремячая грива» с помощью специализиро- 
ванного сервиса опроса «Google». В опросе приняли участие 612 человек.

\section{Результаты и обсуждение}

\section{Анализ вовлеченности ФСС КК}

в проектную деятельность

Проведенный контент-анализ позволил выявить следующие закономерности:

- уровень вовлеченности ФСС КК в проектную деятельность крайне неравномерный и изменяется от 0 до 14 баллов (рис. 3);

- только 18 ФСС из 40 (45\%) имеют признаки вовлеченности в проектную деятельность;

- преимущественно вовлеченность в проектную деятельность осуществляется за счет включенности ФСС в масштабные отраслевые проекты (проекты «ВФСК ГТО», «Зимняя Универсиада», «Спорт - норма жизни» и т. д.);

- только четыре ФСС (10 \%) имеют признаки вовлеченности в проектную деятельность на внутрисистемном уровне, т. е. имеют признаки собственной проектной деятельности;
- только один ФСС КК имеет собственный проект с поставленными целями и сроками исполнения (МАУ «Здоровый мир», г. Красноярск);

- только один ФСС КК имеет подтвержденный на веб-ресурсе опыт участия в социальных проектах на региональном уровне (МАУ СК «Труд», Железногорск).

Полученные закономерности позволяют сделать вывод о крайне низкой вовлеченности ФСС КК в проектную деятельность.

\section{Влияние наличия проектной деятельности на эффективность ФСС КК}

На рис. 4 приведена полученная зависимость экономической эффективности ФСС в виде доходности от интегрального уровня вовлеченности ФСС КК в проектную деятельность.

Как видно на рис. 4, полученное облако значений имеет высокий разброс точек. При этом доходность варьируется от 1,1 до 38,3 \%. При аппроксимации коэффициент корреляции для линейной зависимости составляет не более $2 \%$. Это говорит о том, что связь между доходностью ФСС КК и интегральным

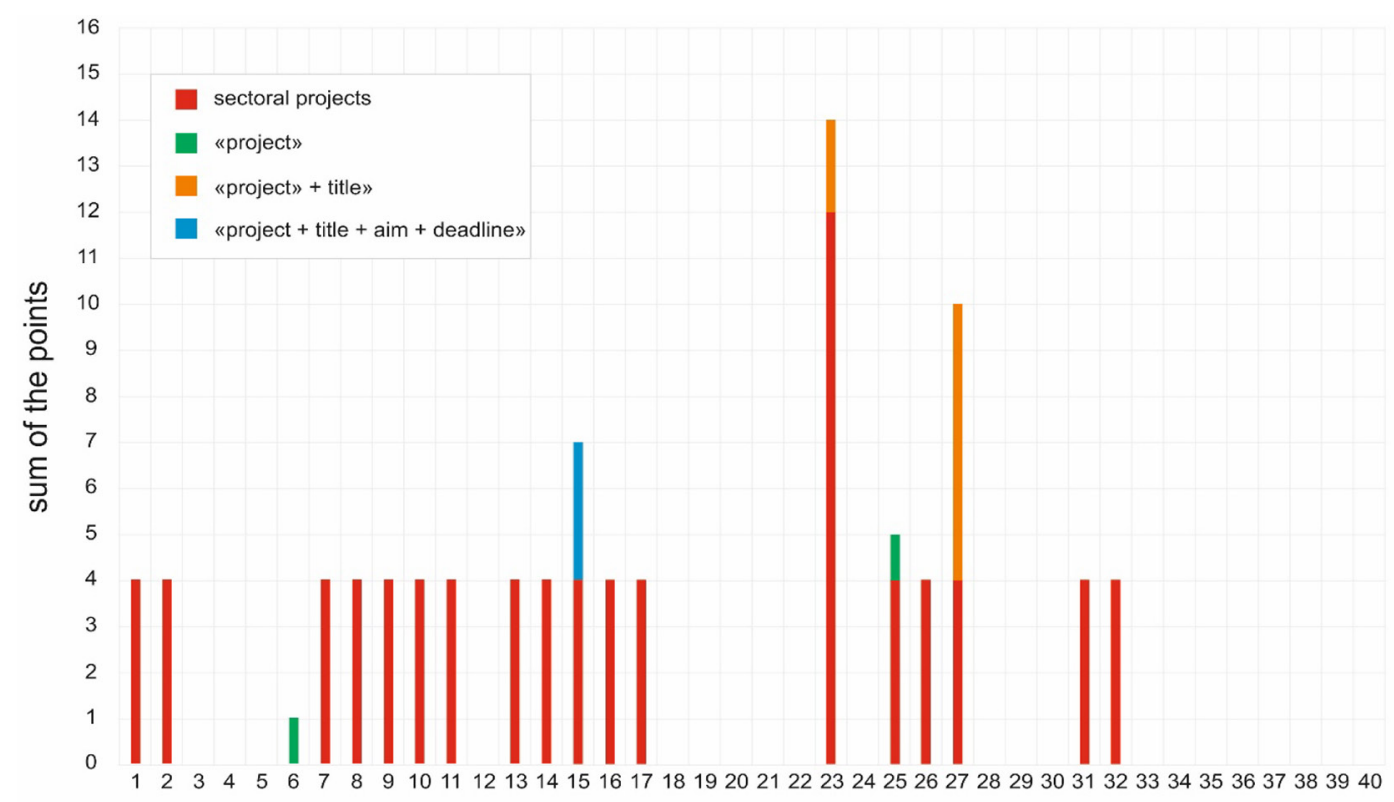

number of sports facilities

Рис. 3. Сравнительный уровень вовлеченности ФСС Красноярского края в проектную деятельность

Fig. 3. Comparative level of involvement of Krasnoyarsk Territory sports facilities in project activities 
уровнем вовлеченности ФСС КК в проектную деятельность практически отсутствует. Качественный анализ данных указывает на то, что существуют другие значимые факторы экономической эффективности ФСС КК. Можно высказать гипотезу, что значимыми из них могут являться: уровень функциональности ФСС, в т. ч. наличие в структуре ФСС плавательных бассейнов, территориальная доступность ФСС, платежеспособность населения, качество услуг и управления ФСС. Скорее всего, малозначимым фактором эффективности является географическое расположение ФСС.

\section{Прогнозная модель эффективности ФСС КК при использовании ПП}

В настоящем разделе приведено обоснование ПП как инструмента повышения экономической эффективности ФСС. Для проведения обоснования было выбрано ФСС «Академия биатлона» (г. Красноярск), являющееся структурным подразделением КГАУ «Региональный Центр Спортивных Сооружений». На начальном этапе обследования характеристик, структуры деятельности и особенностей местоположения ФСС «Академия биатлона» был установлен его высокий рекреационный потенциал (рис. 5). Так, вокруг ФСС находится лесная зона, которая активно используется жителями г. Красноярска для совершения пеших прогулок. В октябре 2018 года на базе данной территории был открыт эко-парк «Гремячая грива».

На следующем этапе была синтезирована организационно-управленческая схема реализации проекта (рис. 6), в результате чего стало возможным оценить номенклатуру ресурсов для реализации проекта. Была установлена значительная готовность учреждения к реализации проекта в материальном плане, однако отсутствовала информация о ключевом факторе - характере спроса на услугу. Для восполнения данного информационного пробела было решено провести опрос потенциальных потребителей услуг.

С целью проведения опроса была разработана анкета, которая включала 10 вопросов. Анкетирование проводилось удаленно - с использованием специализированного сервиса «Google». В анкетировании приняли участие 612 человек. Участниками анкетирования стали сотрудники ФСС «Академия биатлона», спортсмены, студенты и обычные посетители ФСС «Академия биатлона». Среди опрошенных было 52,9 \% женщин и 47,1%

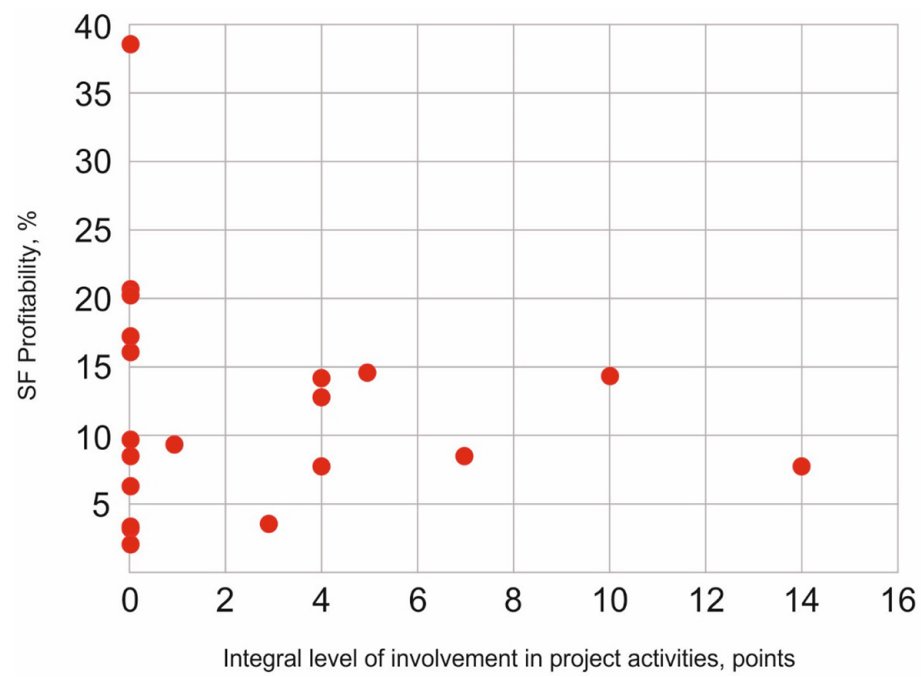

Рис. 4. Эффективность/доходность ФСС как функция интегрального уровня вовлеченности ФСС в проектную деятельность

Fig. 4. Efficiency/profitability of sports facilities as a function of the integral level of involvement of sports facilities in project activities 


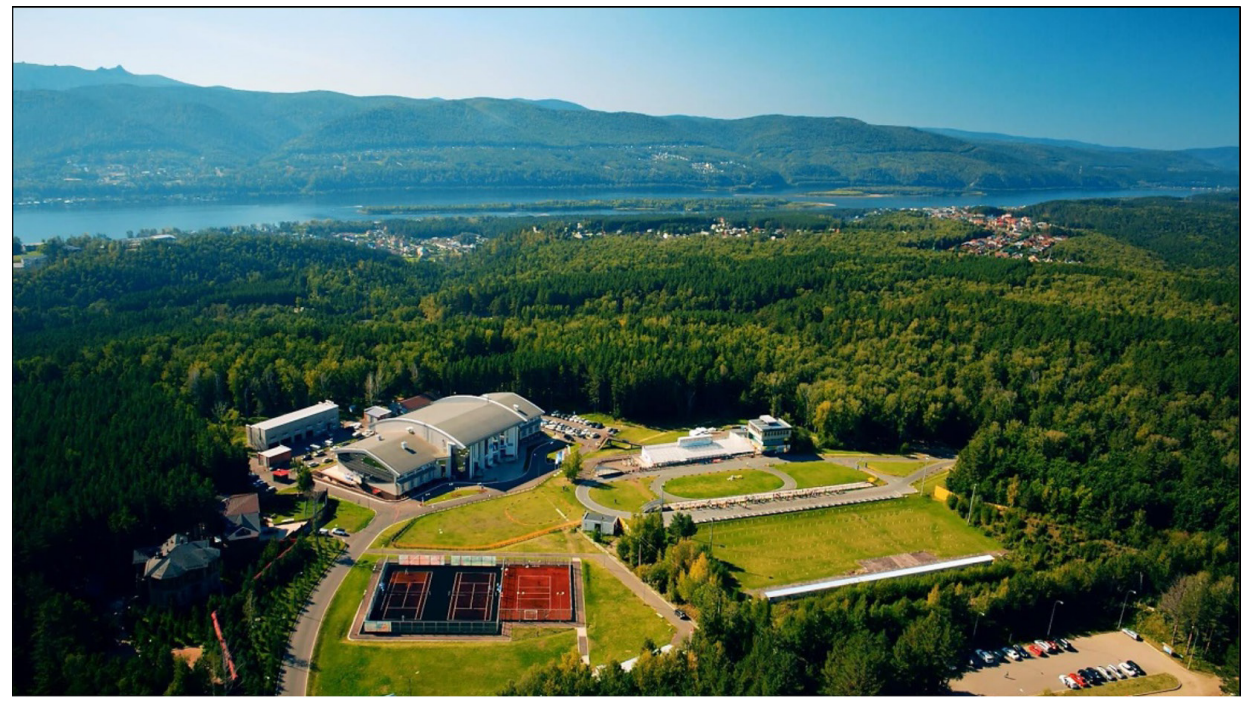

Рис. 5. ФСС «Академия биатлона»

Fig. 5. Biathlon Academy Sports Facility

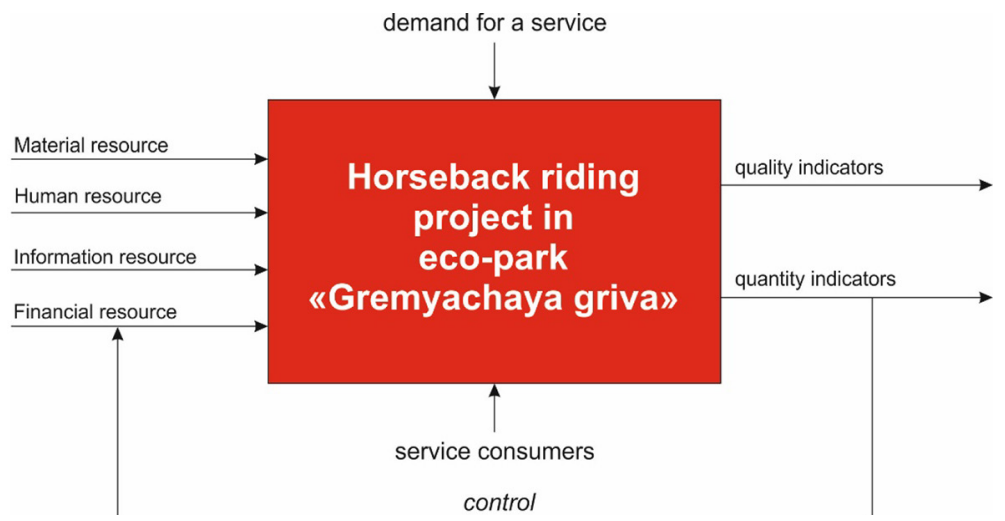

Рис. 6. Организационно-управленческая схема реализации проекта «Конные прогулки в эко-парке «Гремячая грива»

Fig. 6. Organization chart of the project «Horseback riding in the eco-park "Gremyachaya griva"

мужчин. Возраст респондентов находился в диапазоне 25-40 лет. Категория респондентов - сотрудников ФСС «Академия биатлона» была представлена 10,1% от числа опрошенных. Посетители ФСС «Академия биатлона» и эко-парка «Гремячая грива» вошли в 89,9 \% от числа опрошенных респондентов.

На вопросы «Нравятся ли Вам лошади?», «Есть ли желание совершения конных прогулок?» большинство ответили «да», что составило 97,2 \% от числа опрошенных респондентов. Опрос показал, что у 70,5 \% опрошенных респондентов есть навык верховой езды. Благоприятными сезонами для осуществления конных прогулок респонденты посчитали лето и осень. Запуск проекта посчитали актуальным решением 96 \% респондентов.

Таким образом, проведенный опрос показал востребованность проекта «Конные прогулки в эко-парке «Гремячая грива» и позволил перейти к следующему этапу, который включал в себя процедуру детального анализа материально-технического и финансового 
обеспечения проекта. В ходе анализа была установлена необходимость приобретения/ строительства конюшен. Для реализации проекта было запланировано к выделению 1,5 млн руб. Из них около $30 \%$ - собственные средства ФСС «Академия биатлона», а также средства КГАУ «Региональный Центр Спортивных Сооружений» и привлеченных спонсоров.

Далее был осуществлен расчет плановой экономической эффективности проекта. В табл. 1 и на рис. 7 отражены соответствующие показатели доходности. Как видно, при полугодичном использовании услуги конных прогулок предлагаемый к реализации проект позволяет повысить доходность ФСС до 5,13 \%, что в 2 раза выше текущих значений (за 2019 год).

Проведенная поэтапная проработка проекта позволила перейти к финальной стадии его подготовки - оформлению устава проекта. Основные элементы устава комплексно отражают сущность проекта и позволяют институализировать проект на базе ФСС.

Таким образом, экономическое моделирование показывает, что проект может быть успешно реализован. Подобные проекты с успехом реализовываются за рубежом. Например, в Германии действует проект «Конно-спортивный комплекс». За период его существования было проведено 3600 спортивных мероприятий, состоялось
68000 турниров при 1460000 участниках (Skopin, 2012).

\section{Заключение}

Проведенная аналитическая работа по изучению деятельности 40 ФСС КК, как и предполагалось, продемонстрировала крайне низкий уровень вовлеченности учреждений в проектную деятельность. Признаки такой вовлеченности имеют не более $45 \%$ ФСС КК. В основном проанализированные ФСС КК включены в масштабные федеральные проекты вышестоящих отраслевых учреждений. Признаки наличия собственной проектной деятельности зафиксированы лишь у $10 \%$ ФСС. Анализ экономической эффективности ФСС КК в виде расчета процента доходности ФСС позволил установить довольно высокий разброс значений - от 1,1 до $38,3 \%$. Это дает возможность сделать заключение о неравномерной экономической эффективности рассмотренных авторами ФСС КК. Корреляционный и графический анализ соотношения показателей вовлеченности ФСС КК в проектную деятельность и показателя экономической эффективности в виде доходности ФСС КК позволил установить фактическое отсутствие между ними связи (коэффициент корреляции не более $2 \%$ ). Это означает то, что на сегодняшний момент проектная деятельность не является значимым фактором эффективности рассмо-

Таблица 1. Расчет доходности ФСС при внедрении проекта

Table 1. Profitability of the sports facility during project implementation

\begin{tabular}{|c|c|c|c|}
\hline Год & Выручка, тыс. руб. & $\begin{array}{c}\text { Общая сумма расходов, } \\
\text { тыс. руб. }\end{array}$ & Доходность, \% \\
\hline 2012 & 934,78 & 57858,68 & 1,62 \\
\hline 2013 & 1714,25 & 62022,75 & 2,76 \\
\hline 2014 & 2389,59 & 59459,03 & 4,02 \\
\hline 2015 & 3265,39 & 85231,69 & 3,83 \\
\hline 2016 & 2233,48 & 67531,65 & 3,31 \\
\hline 2017 & 2122,88 & 70655,82 & 3,00 \\
\hline 2018 & 1582,33 & 78573,83 & 2,01 \\
\hline 2019 & 2605,10 & 101830,8 & 2,56 \\
\hline $2020(\min )$ & 3010,10 & 103390,8 & 2,91 \\
\hline $2020(\max )$ & 5305,10 & 103510,8 & 5,13 \\
\hline
\end{tabular}




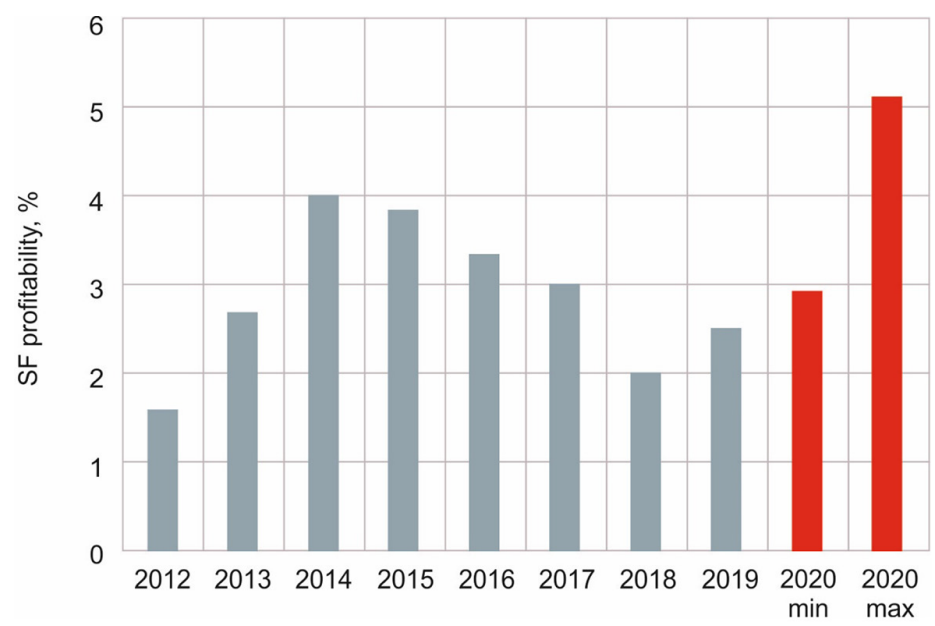

Рис. 7. Фактическая и прогнозируемая доходность ФСС «Академия биатлона» до и после внедрения проекта

Fig. 7. Actual and projected profitability of the Biathlon Academy Sports Facility before and after the implementation of the project

тренных авторами ФСС КК. Проведенное моделирование на примере разработанного проекта «Конные прогулки в эко-парке «Гремячая грива» показывает возможности проектного подхода в управлении ФСС КК. Так, реализация только этого проекта позволяет прогнозировать рост доходности ФСС «Академия биатлона» почти в 2 раза.

\section{Список литературы / References}

Bertalanffy, K.L. (1960). General System Theory. Foundations, Development, Applications. New York, George Braziller, 289 p.

Biiak, L.L., Nenuzhenko, S.A. (2017). The role of project management in the implementation of priority state projects [Rol' proektnogo upravleniia v realizatsii prioritetnykh gosudarstvennykh proektov]. In Materialy V mezhdunarodnoi nauchnoi konferentsii «Aktual'nye voprosy ekonomiki i upravleniia» [Materials of the 5th international conference "Actual issues of economic and management]. Moscow, 12-14.

Burkov, V.N. (2001). Teoriia grafov v upravlenii organizatsionnymi sistemami [Graph theory in the management of organizational systems]. Moscow, Sinteg, 124 p.

Degtiarev, Yu.I. (1996). Sistemnyi analiz i issledovanie operatsyi [Systems analysis and operations research]. Moscow, Vysshaia shkola, $334 \mathrm{p}$.

Dostatochno Obshchaia Teoriia Upravleniia: postanovochnye materialy uchebnogo kursa fakul'teta prikladnoi matematiki - protsessov upravleniia Sankt-Peterburgskogo gosudarstvennogo universiteta [Fairly General Management Theory: staging materials of the educational course of the Faculty of applied mathematics - control processes of Saint-Petersburg State University] (2011). Available at: https://www. vodaspb.ru/arhive/vp_sssr/knigi/dotu_2011/dotu_a4_20110626.pdf

Dugalić, S., Krsteska A. (2013). Challenges of sports facilities and projects management in the XXI century. In SPORT - Science and Practice, 3(2), 59-77.

Fried, G. (2015). Managing sport facilities. Champaign, Human Kinetics, 440 p.

Gubko, M.V., Novikov, D.A. (2005). Teoriia igr v upravlenii organizatsionnymi sistemami [Game theory in the management of organizational systems]. Moscow, IPU RAN, $138 \mathrm{p}$.

Kozhevnikov, S.A. (2016). Proektnoe upravlenie kak instrument povysheniia effektivnosti organov ispolnitel'noi vlasti [Project management as a tool for enhancing the performance of government executive 
bodies]. In Voprosy Territorial 'nogo Razvitiia [Territorial Development Issues], 5(35), available at: http:// vtr.isert-ran.ru/article/2037?_lang=en.

Mironenko, N.V., Leonova, O.V. (2017). Evoliutsiia razvitiia proektnogo upravleniia v Rossii i za rubezhom [Evolution of project management development in Russia and abroad]. In Upravlencheskoe Konsul'tirovanie [Administrative Consulting], 6(102), 65-72.

Novikov, D.A. (2011). Metodologiia urpavleniia [Management methodology]. Moscow, Librokom, $128 \mathrm{p}$.

Obozhina, D.A. (2017). Upravlenie fizkul'turno-sportivnoi organizatsiei: uchebnoe posobie [Sports organization management]. Ekaterinburg, Izdatel'stvo Ural'skogo Universiteta, 76 p.

Olkhovskii, R.M., Solntsev, I.V., Osokin, N.A. (2018). Proektnoe upravlenie v sfere fizicheskoi kul'tury i sporta [Project management in the field of physical education and sports]. In Gosudarstvennaia sluzhba [Public administration], 4, 34-39.

Pereverzin, I.I. (2006). Menedzhment sportivnykh organizatsii: uchebnoe posobie [Management of sports organizations]. Moscow, Fizkul'tura i sport, $434 \mathrm{p}$.

Pochinkin, A.V. (2010). Menedzhment $v$ sfere fizicheskoi kul'tury i sporta: uchebnoe posobie [Management in the field of physical education and sports]. Malakhovka, Izdatel'stvo «MGAFK», $164 \mathrm{p}$.

Puchkov, N.P. (2013). Matematicheskaia statistika. Primenenie v professional'noi deiatel'nosti: uchebnoe posobie [Mathematical statistics. Application in professional activities: tutorial]. Tambov, Izdatel'stvo «TGTU», $80 \mathrm{p}$.

Savchenko, Ya.V., Mikhailova, N.S. (2017). Model' kontrakta zhiznennogo tsikla v proektakh gosudarstvenno-chastnogo partnerstva $\mathrm{v}$ sfere fizicheskoi kul'tury i sporta [Model of a life cycle contract in PPP projects in physical education and sport], In Rossiiskoe predprinimatel'stvo [Russian Entrepreneurship], 18(24), 4249-4260.

Sawyer, T.H., Judge, L.W., Gimbert, T.L. (2015). Facility Management for Physical Activity and Sport. Second Edition. Sagamore Publishing LLC, 77 p.

Skopin, O.V. (2012). Mesto i rol' proektnogo upravleniia v sfere fizkul'turno-ozdorovitel'nykh uslug [The place and role of project management in the field of sports and recreation services]. In Sovremennye Tekhnologii Upravleniia [Modern Management Technology], 3(15), 49-54.

Stadnichenko, A.F. (2017). Proektnoe upravlenie kak instrument realizatsii strategii razvitiia kompanii [Project management as a tool for implementing the development strategy of the company]. In Molodoi Uchenyi [Young Scientist], 23(157), 67-71.

Tarshis, E.Ya. (2013). Kontent-analiz: Printsipy metodologii [Content-analysis: Principles of methodology]. Moscow, Librokom, 176 p.

Trofimov, V.V. (2019). Upravlenie proektami: uchebnoe posobie [Project management: tutorial]. St.-Petersburg, SPBGEU, 174 p.

Venttsel', E.S. (1972). Issledovanie operatsii [Operations research]. Moscow, Sovetskoe radio, 552 p.

Vershlovskii, S.G. (2006). Kontent-analiz v pedagogicheskom issledovanii: uchebnoe posobie [Content-analysis in pedagogical research]. St.-Petersburg, Izdatel'stvo «PAPPO», $61 \mathrm{p}$.

Wiener, N. (1948). Cybernetics or control and communication in the animal and the machine. Cambridge, Massachusetts, MIT Press, $211 \mathrm{p}$.

Zarenkov, V.A. (2006). Upravlenie proektami: uchebnoe posobie [Project management: tutorial]. St.-Petersburg, Izdatel'stvo «ASV», $312 \mathrm{p}$.

Zubarev, S.N., Smirnova I.I., Grishina N.S., Kucherov S.M., Mikhalev V.V., Morozov S.S., Sidorova S.L., Favorskaia Ya.V., Yakovenko D.A. (2008). Otsenka effektivnosti ispol'zovaniia soprtivnykh ob"ektov [Evaluation of the efficiency of using sports facilities]. Moscow, Moskomsport, $112 \mathrm{p}$. 